\title{
Development of Molecular Diagnostic System with High Sensitivity for the Detection of Human Sapovirus from Water Environments
}

\author{
Siwon Lee $e^{1,2, *}$, Kyung Seon Bae $\mathrm{B}^{3, * *}$, Jin-Young Lee ${ }^{2, * *}$, Youn-Lee Joo ${ }^{3, * *}$, \\ Ji-Hae Kim $^{3, * *}$ and Kyung-A You ${ }^{3, \dagger, * * *}$ \\ ${ }^{1}$ Department of Biomedical Laboratory Science, Shinhan University, Uijeongbu 11644, Korea \\ ${ }^{2}$ R\&D Team, LSLK Co., Gimpo, Gyeonggi 10111, Korea \\ ${ }^{3}$ Water Supply and Sewerage Research Division, National Institute of Environmental Research, \\ Incheon 22689, Korea
}

\begin{abstract}
Human Sapovirus (HuSaV) is one of the major causes of acute gastroenteritis in humans, and it is used as a molecular diagnostic technique based on polymerase chain reaction (PCR) from humans, food, shellfish, and aquatic environments. In this study, the HuSaV diagnosis technique was used in an aquatic environment where a number of PCR inhibitors are included and pathogens, such as viruses, are estimated to exist at low concentration levels. HuSaV-specific primers are improved to detect 38 strains registered in the National Center for Biotechnology Information (NCBI). The established optimal condition and the composition, including the RT-nested PCR primers and SL ${ }^{\circledR}$ Non-specific reaction inhibitor, were found to have 100 times higher sensitivity based on $\mathrm{HuSaV}$ plasmid than the previously reported methods (100 ag based on HuSaV plasmid $1 \mathrm{ng} / \mu \mathrm{L}$ ). Through an artificial infection test, the developed method was able to detect at least $1 \mathrm{fg} / \mu \mathrm{L}$ of $\mathrm{HuSaV}$ plasmid contaminated with total nucleic acid extracted from groundwater. In addition, RT-nested PCR primer sets for $\mathrm{HuSaV}$ detection can react, and a positive control is developed to verify false positives. This study is expected to be used as a HuSaV monitoring method in the future and applied to the safety response to HuSaV from water environments.
\end{abstract}

Key Words: Human Sapovirus, HuSaV, Positive control, SL ${ }^{\circledR}$ Non-specific reaction inhibitor, Water environments

Human Sapovirus (HuSaV)는 Norovirus (NoV), Rotavirus A (RV-A), Astrovirus (AstV), enteric Adenovirus (eAdV)와 함 께 사람 급성 위장염의 주요 원인 바이러스 중 하나이다 (Oka et al., 2015; Hwang et al., 2015). 국내에서는 영유아에서 만 12세 어린이들에게 주로 발생이 보고되었으며, 8 12월 에 발병률이 높았다(Hwang et al., 2015; KCDC, 2019; Cho, $2018 b) . H u S a V$ 는 분변-구강 경로로 감염 및 오염되므로 사람, 식품, 패류, 수계 환경 등으로부터 잠재적 존재 가 능성이 있으므로 각 매질에서의 모니터링 등 감시가 중
요하다(KCDC, 2015; KMFDS, 2015; NIER, 2016). HuSaV 진단 및 모니터링 방법은 중합효소연쇄반응(polymerase chain reaction; PCR) 기반의 분자진단 기법이 주로 활용되 고 있다(Cho, 2018a; Fukuda et al., 2006; Oka et al., 2006; Shigemoto et al., 2011). 그러나 시료 중 지하수 등 수계 환 경은 사람, 식품, 패류 등 다른 매질 대비 병원체가 상대 적으로 낮은 수준 농도 및 다양한 유전자형의 존재가 추 정되고, 환경 시료는 $\mathrm{PCR}$ 검사 시 부식산 등 부식질 물 질, 풀미산, 금속이온, 폴리페놀, 염소, 철분 등 다양한 저

Received: January 15, 2021 / Revised: February 24, 2021 / Accepted: March 15, 2021

* Professor, ${ }^{* *}$ Researcher, ${ }^{* * *}$ Senior Researcher.

${ }^{\dagger}$ Corresponding author: Kyung-A You. Water Supply and Sewerage Research Division, National Institute of Environmental Research, Incheon 22689 , Korea. Tel: +82-32-560-8353, Fax:+82-32-563-7085, e-mail: angelka@korea.kr

(C) The Korean Society for Biomedical Laboratory Sciences. All rights reserved.

(C) This is an Open Access article distributed under the terms of the Creative Commons Attribution Non-Commercial License (http://creativecommons.org/licenses/by-nc/3.0/) which permits unrestricted non-commercial use, distribution, and reproduction in any medium, provided the original work is properly cited. 
해 물질을 포함하고 있어 매질의 특성에 따른 고감도 검사 기법이 필요하였다(Cho, 2018b; Dalecka and Mezule, 2018; Schrader et al., 2012). 또한, 국내 경기도에서 최근 HuSaV-GI.3 유형의 최초 보고(Cho et al., 2020)되는 등, 바 이러스의 변이에 따른 genotyping의 중요성이 부각되면서 후속 유전형 분석이 가능한 conventional $\mathrm{PCR}$ 의 활용이 권 장되고 있다(NIER, 2016). 이로 인해 최근 다양한 종류의 $\mathrm{HuSaV}$ 염기서열이 미국국립생물정보센터에 등록되고 있 으며 기존 보고된 몇몇의 $\mathrm{HuSaV}$ 검출용 RT-PCR 프라이 머 조합은 최근 등록된 $\mathrm{HuSaV}$ 의 염기서열에 결합하지 못할 가능성이 발견되었으나, 지하수 등 수계 환경 중 잠 재적 존재 가능성이 있는 다양한 $\mathrm{HuSaV}$ 검출을 위한 분 자진단 기반 검사 기법에 대한 연구는 미흡한 상황이다. 한편, 분자진단 시 검사의 신뢰성 향상을 위해 양성대조 물질(i.e. viral plasmid, RNA transcript 등)이 사용되고 있지만, 검사 전 처리 등 조작 시 양성대조 물질로부터의 오염으 로 인해 위 양성(false positive)을 검정 할 수 있는 시스템 이 필요하다(Lee, 2013). 따라서 이번 연구에서는 $\mathrm{HuSaV}$ 의 다양한 종류의 염기서열 부착이 가능한 RT-PCR 및 nested PCR 프라이머 조합을 개발 및 최적의 증폭반응을 위한 조건을 확립하였으며, 위 양성 검정이 가능한 장치 가 포함된 양상대조 물질을 개발하는 등 수계 환경에서 $\mathrm{HuSaV}$ 모니터링을 위한 분자진단 시스템을 개발하였다.

$\mathrm{HuSaV}$ 는 NCBI accession number KP298674 4,440-6,439 뉴클레오타이드(nucleotide; nt)를 기준으로 $2,000 \mathrm{nt}$ 및 참 고바이러스 6종(Aichivirus A, Astrovirus, Hepatitisvirus A, Hepatitisvirus E, Norovirus 및 Rotavirus-A)의 유전자 단편을 합성하였다[Marcrogen (Seoul, Korea)]. HuSaV 검출용 후보 RT-PCR 및 nested PCR 프라이머 조합은 기존 보고된 방 법들[Khamrin et al., 2011; Kitajima et al., 2010; Korea Centers for Disease Control and Prevention (KCDC), 2015; Korea Ministry of Food and Drug Safety (KMFDS), 2015; Kumthip et al., 2020; Liu et al., 2015; Oka et al., 2015; Shigemoto et al., 2011; Thwiny et al., 2015]을 기준으로 등록된 38개 종류의 $\mathrm{HuSaV}$ 유형에 결합이 가능하도록 뉴클레오타이드 레터코 드로 변형하였다. 변형한 PCR 프라이머는 Oligo Calculator version 3.27로 self annealing, potential hairpin formation 등을 점검하여 최정 정방향 3 개 및 역방향 2 개의 $\mathrm{PCR}$ 프라이 머들을 설계 및 제작 및 설계한 프라이머들을 조합한 6 개 의 후보 RT-PCR 프라이머 조합을 구성하였다(Table 1). $\mathrm{HuSaV}$ 검출용 6 개의 후보 RT-PCR 프라이머 조합에 대한 검출 민감도 및 참고 바이러스 6종 핵산에 대한 비 특이
적 반응을 검정하였다. $\mathrm{HuSaV}$ plasmid $1 \mathrm{ng} / \mu \mathrm{L}$ 기준 $10^{-3}$ 에 서 $10^{-8}$ 까지 희석하여 검출 민감도를 분석하였으며, PCR 조성과 조건은 국립환경과학원 수인성바이러스 검사법과 동일하게 수행하였다(NIER, 2016). $\mathrm{HuSaV}$ 검출용 후보 RT-PCR 프라이머 조합에서는 $10^{-3}$ 에서 $10^{-5}$ 수준의 검출 민감도가 나타났으며, 이 중 가장 우수한 검출 민감도를 보인 후보 RT-PCR 프라이머 조합은 \#1과 \#5였다. \#1과 $\# 5$ 에 대하여 $10^{-5}$ 에서 $10^{-6}$ 까지의 검출 민감도를 추가로 분석한 결과 $781 \mathrm{nt}$ 의 산물이 형성되는 \#1를 선발하였다 (Fig. 1A). RT-PCR 프라이머 조합 \#1은 참고바이러스 6종 에 비 특이적 반응이 나타나지 않아 $\mathrm{HuSaV}$ 만을 특이적 으로 검출할 수 있을 것으로 추정되었다(자료 미 제공). 또한, 지하수 등 시료에서 낮은 수준의 $\mathrm{HuSaV}$ 오염의 경 우 고감도 검출을 위하여 RT-PCR 프라이머 조합은 \#1의 산물로부터 증폭이 가능한 nested PCR 프라이머 조합을 선발하였다. RT-PCR 프라이머 조합 \#1로부터 3개의 후보 nested PCR 프라이머 조합(\#1-1, \#1-2 및 \#1-3)을 설계하였 으며, 검출 민감도를 분석한 결과 $491 \mathrm{nt}$ 를 최종 산물로 하는 \#1-1이 $10^{-7}$ 수준으로 다른 2개 조합에 비해 약 10 배 수준 우수하게 나타났다(Fig. 1B). HuSaV plasmid를 주형으 로 이번 연구에서 개발한 RT-nested 프라이머 조합을 사 용하여 최종 증폭된 산물을 염기서열 분석한 결과, $\mathrm{HuSaV}$ (NCBI accession number KP298674) 100.0\% 결과가 나타났 다(자료 미 제공). 한편 이번 연구에서 개발한 $\mathrm{HuSaV}$ 검 출용 RT-PCR 및 nested PCR 프라이머 조합은 기존 보고 된 7개의 RT-PCR 및 RT-nested PCR 방법에 비해 RT$\mathrm{PCR}$ 수준에서 약 동등-1000배 이상, nested PCR 수준에서 는 약 $100 \sim 1,000$ 배 우수한 검출 민감도가 나타남에 따라 (Fig. 2) 시료 내 낮은 수준의 $\mathrm{HuSaV}$ 존재 시에도 검출이 기대된다.

개발한 PCR 및 nested PCR의 시료 검정을 위하여, 국립 환경과학원 고시 제 2017-50에 따라 지하수 시료 20점을 채취, 탈리 및 농축하였으며, 최종 농축액으로부터 RNeasy Mini Kit (Qiagen, Germany)의 매뉴얼에 따라 total RNA를 추출하였다. RT-PCR은 AccuPower ${ }^{\circledR}$ RT/PCR PreMix (Bioneer, Daejeon, Korea), nested PCR은 AccuPower ${ }^{\circledR}$ HotStart PCR PreMix (Bioneer)를 사용하였고, 환경 시료에서 나타나는 비 특이적 반응억제를 위해 $\mathrm{SL}^{\circledR}$ Non-specific reaction inhibitor (LSLK, Gyeonggi, Korea) $3 \mu \mathrm{L}$ 를 포함하여 최종 $20 \mu \mathrm{L}$ volume으로 반응하였다. RT-nested PCR 결과, 20개 지하수 시료에서 분석 결과 모두 음성으로 분석됨에 따라(Fig. 3A), $\mathrm{HuSaV}$ plasmid의 지하수에서 추출한 핵산에 인위감염 하 
Table 1. RT- and nested PCR information for the detection of human Sapovirus (HuSaV)

\begin{tabular}{|c|c|c|c|c|c|c|c|c|c|c|}
\hline & \multirow{3}{*}{ Division } & \multirow{3}{*}{$\begin{array}{l}\text { PCR } \\
\text { type }\end{array}$} & \multicolumn{5}{|c|}{ Primer information } & \multirow{3}{*}{$\begin{array}{l}\text { Length } \\
\text { (nt) }\end{array}$} & \multirow{3}{*}{ References } & \multirow{3}{*}{ Remark } \\
\hline & & & \multirow{2}{*}{ Name } & \multirow{2}{*}{ Sequence $\left(5^{\prime} \rightarrow 3^{\prime}\right)$} & \multirow{2}{*}{$\begin{array}{l}\text { Mer } \\
\text { (nt) }\end{array}$} & \multicolumn{2}{|c|}{ Location $^{*}$} & & & \\
\hline & & & & & & Start & End & & & \\
\hline \multirow{16}{*}{$\begin{array}{l}\text { Candidate } \\
\text { RT-nested } \\
\text { PCR primer } \\
\text { ses in this } \\
\text { study }\end{array}$} & \multirow{2}{*}{$\begin{array}{l}\text { RT-PCR } \\
\text { primer set \#1 }\end{array}$} & \multirow{2}{*}{ RT-PCR } & SaV-F5098m & GCYTGGTTYATAGGTGGTAC & 20 & 5,098 & 5,117 & \multirow{2}{*}{781} & \multirow{2}{*}{$\begin{array}{l}\text { This } \\
\text { study }\end{array}$} & $\begin{array}{l}\text { SV-F11 base } \\
\text { modified }\end{array}$ \\
\hline & & & SaV-R5878m & CWGGTGAIMHICCATTKTCCAT & 22 & 5,857 & 5,878 & & & $\begin{array}{l}\text { SV-R1 base } \\
\text { modified }\end{array}$ \\
\hline & \multirow{2}{*}{$\begin{array}{l}\text { RT-PCR } \\
\text { primer set \#2 }\end{array}$} & \multirow{2}{*}{ RT-PCR } & SaV-F5157m & AITAGTGTTTGARATGGAGGG & 21 & 5,157 & 5,177 & \multirow{2}{*}{435} & $\begin{array}{l}\text { This } \\
\text { study }\end{array}$ & $\begin{array}{l}\text { SV-F21 base } \\
\text { modified }\end{array}$ \\
\hline & & & SV-R2 & GWGGGRTCAACMCCWGGTGG & 20 & 5,572 & 5,591 & & {$[2,3]$} & $\begin{array}{l}\text { Same as } \\
\text { reference }\end{array}$ \\
\hline & \multirow{2}{*}{$\begin{array}{l}\text { RT-PCR } \\
\text { primer set \#3 }\end{array}$} & \multirow{2}{*}{ RT-PCR } & SaV-F5101m & TGGTTYATAGGTGGTRCAG & 19 & 5,101 & 5,119 & \multirow{2}{*}{778} & \multirow{2}{*}{$\begin{array}{l}\text { This } \\
\text { study }\end{array}$} & $\begin{array}{l}\text { SV-F11 base } \\
\text { modified }\end{array}$ \\
\hline & & & SaV-R5878m & CWGGTGAIMHICCATTKTCCAT & 22 & 5,857 & 5,878 & & & $\begin{array}{l}\text { SV-R1 base } \\
\text { modified }\end{array}$ \\
\hline & \multirow{2}{*}{$\begin{array}{l}\text { RT-PCR } \\
\text { primer set \#4 }\end{array}$} & \multirow{2}{*}{ RT-PCR } & SaV-F5101m & TGGTTYATAGGTGGTRCAG & 19 & 5,101 & 5,119 & \multirow{2}{*}{491} & $\begin{array}{l}\text { This } \\
\text { study }\end{array}$ & $\begin{array}{l}\text { SV-F11 base } \\
\text { modified }\end{array}$ \\
\hline & & & SV-R2 & GWGGGRTCAACMCCWGGTGG & 20 & 5,572 & 5,591 & & {$[2,3]$} & $\begin{array}{l}\text { Same as } \\
\text { reference }\end{array}$ \\
\hline & \multirow{2}{*}{$\begin{array}{l}\text { RT-PCR } \\
\text { primer set \#5 }\end{array}$} & \multirow{2}{*}{ RT-PCR } & SaV-F5098m & GCYTGGTTYATAGGTGGTAC & 20 & 5,098 & 5,117 & \multirow{2}{*}{494} & $\begin{array}{l}\text { This } \\
\text { study }\end{array}$ & $\begin{array}{l}\text { SV-F11 base } \\
\text { modified }\end{array}$ \\
\hline & & & SV-R2 & GWGGGRTCAACMCCWGGTGG & 20 & 5,572 & 5,591 & & {$[2,3]$} & $\begin{array}{l}\text { Same as } \\
\text { reference }\end{array}$ \\
\hline & \multirow{2}{*}{$\begin{array}{l}\text { Nested PCR } \\
\text { primer set \#1-1 }\end{array}$} & \multirow{6}{*}{$\begin{array}{l}\text { Nested } \\
\text { PCR }\end{array}$} & SaV-F5101m & TGGTTYATAGGTGGTRCAG & 19 & 5,101 & 5,119 & 491 & $\begin{array}{l}\text { This } \\
\text { study }\end{array}$ & $\begin{array}{l}\text { SV-F11 base } \\
\text { modified }\end{array}$ \\
\hline & & & SV-R2 & GWGGGRTCAACMCCWGGTGG & 20 & 5,572 & 5,591 & & {$[2,3]$} & $\begin{array}{l}\text { Same as } \\
\text { reference }\end{array}$ \\
\hline & Nested PCR & & SaV-F5098m & GCYTGGTTYATAGGTGGTAC & 20 & 5,098 & 5,117 & 404 & $\begin{array}{l}\text { This } \\
\text { study }\end{array}$ & $\begin{array}{l}\text { SV-F11 base } \\
\text { modified }\end{array}$ \\
\hline & primer set \#1-2 & & SV-R2 & GWGGGRTCAACMCCWGGTGG & 20 & 5,572 & 5,591 & & {$[2,3]$} & $\begin{array}{l}\text { Same as } \\
\text { reference }\end{array}$ \\
\hline & Nested PCR & & SaV-F5157m & AITAGTGTTTGARATGGAGGG & 21 & 5,157 & 5,177 & 435 & $\begin{array}{l}\text { This } \\
\text { study }\end{array}$ & $\begin{array}{l}\text { SV-F21 base } \\
\text { modified }\end{array}$ \\
\hline & primer set \#1-3 & & SV-R2 & GWGGGRTCAACMCCWGGTGG & 20 & 5,572 & 5,591 & & {$[2,3]$} & $\begin{array}{l}\text { Same as } \\
\text { reference }\end{array}$ \\
\hline & Pef $\# 1$ & RTPCP & $\begin{array}{l}\text { SV-F21 } \\
(5157-5177)\end{array}$ & ANTAGTGTTTGARATGGAGGG & 21 & 5,157 & 5,177 & 722 & Shigemoto & \\
\hline & & & $\begin{array}{l}\text { SV-R1 } \\
(5857-5878)\end{array}$ & CWGGTGAMACMCCATTKTCCAT & 22 & 5,857 & 5,878 & & et al., 2011 & \\
\hline & & RT-PCR & $\begin{array}{l}\text { SV-F11 } \\
(5098-5117)\end{array}$ & GCYTTGTTYATAGGTGGTAC & 20 & 5,098 & 5,117 & 781 & & \\
\hline $\begin{array}{l}\text { Reference } \\
\text { RT or RT- }\end{array}$ & Peft? & КНГСК & $\begin{array}{l}\text { SV-R1 } \\
(5857-5878)\end{array}$ & CWGCTGAMACMCCATTKTCCAT & 22 & 5,857 & 5,878 & 101 & Oka et al., & \\
\hline $\begin{array}{l}\text { nested PCR } \\
\text { primer sets }\end{array}$ & & Nested & $\begin{array}{l}\text { SV-F21 } \\
(5157-5177)\end{array}$ & ANTAGTGTTTGARATGGAGGG & 21 & 5,157 & 5,177 & 125 & 2015 & \\
\hline & & PCR & $\begin{array}{l}\text { SV-R2 } \\
(5572-5591)\end{array}$ & GWGGGRTCAACMCCWGGTGG & 20 & 5,572 & 5,591 & 430 & & \\
\hline & & & $\begin{array}{l}\text { SV-F11 } \\
(5098-5117)\end{array}$ & GCYTTGTTYATAGGTGGTAC & 20 & 5,098 & 5,117 & & Kitajima & \\
\hline & NCI.AJ & 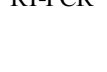 & $\begin{array}{l}\text { SV-R1 } \\
(5857-5878)\end{array}$ & CWGCTGAMACMCCATTKTCCAT & 22 & 5,857 & 5,878 & 101 & et al., 2010 & \\
\hline
\end{tabular}


Table 1. RT- and nested PCR information for the detection of human Sapovirus (HuSaV) (Continued)

\begin{tabular}{|c|c|c|c|c|c|c|c|c|c|c|}
\hline & \multirow{3}{*}{ Division } & \multirow{3}{*}{$\begin{array}{l}\text { PCR } \\
\text { type }\end{array}$} & \multicolumn{5}{|c|}{ Primer information } & \multirow{3}{*}{$\begin{array}{l}\text { Length } \\
\text { (nt) }\end{array}$} & \multirow{3}{*}{ References } & \multirow{3}{*}{ Remark } \\
\hline & & & \multirow{2}{*}{ Name } & \multirow{2}{*}{ Sequence $\left(5^{\prime} \rightarrow 3^{\prime}\right)$} & \multirow{2}{*}{$\begin{array}{l}\text { Mer } \\
\text { (nt) }\end{array}$} & \multicolumn{2}{|c|}{ Location $^{*}$} & & & \\
\hline & & & & & & Start & End & & & \\
\hline \multirow{12}{*}{$\begin{array}{l}\text { Reference } \\
\text { RT or RT- } \\
\text { nested PCR } \\
\text { primer sets }\end{array}$} & \multirow{2}{*}{ Ref.\#3 } & \multirow{2}{*}{$\begin{array}{l}\text { Nested } \\
\text { PCR }\end{array}$} & $\begin{array}{l}\text { 1245Rfwd } \\
\text { (5161-5177) }\end{array}$ & TAGTGTTTGARATGGAGGG & 19 & 5,159 & 5,177 & \multirow{2}{*}{433} & \multirow{2}{*}{$\begin{array}{l}\text { Kitajima } \\
\text { et al., } 2010\end{array}$} & \\
\hline & & & $\begin{array}{l}\text { SV-R2 } \\
(5572-5591)\end{array}$ & GWGGGRTCAACMCCWGGTGG & 20 & 5,572 & 5,591 & & & \\
\hline & \multirow{2}{*}{ Ref.\#4 } & \multirow{2}{*}{ RT-PCR } & SLV5317 & CTCGCCACCTACRAWGCBTGGTT & 23 & 5,083 & 5,105 & \multirow{2}{*}{434} & \multirow{2}{*}{$\begin{array}{l}\text { Kumthip } \\
\text { et al., } 2020\end{array}$} & \\
\hline & & & SLV5749 & CGGRCYTCAAAVSTACCBCCCCA & 23 & 5,494 & 5,516 & & & \\
\hline & \multirow{4}{*}{ Ref.\#5 } & \multirow{2}{*}{ RT-PCR } & $\begin{array}{l}\text { SV-F14 } \\
(5074-)\end{array}$ & GAACAAGCTGTGGCATGCTAC & 21 & 5,074 & 5,094 & \multirow{2}{*}{803} & \multirow{4}{*}{$\begin{array}{l}\text { Liu et al., } \\
2015\end{array}$} & \\
\hline & & & $\begin{array}{l}\text { SV-R14 } \\
(-5876)\end{array}$ & GGTGAGMMYCCATTCTCCAT & 20 & 5,857 & 5,876 & & & \\
\hline & & \multirow{2}{*}{$\begin{array}{l}\text { Nested } \\
\text { PCR }\end{array}$} & $\begin{array}{l}\text { SV-F22 } \\
(5154-)\end{array}$ & SMWAWTAGTGTTTGARATG & 19 & 5,154 & 5,172 & \multirow{2}{*}{438} & & \\
\hline & & & $\begin{array}{l}\text { SV-R2 } \\
(-5591)\end{array}$ & GWGGGRTCAACMCCWGGTGG & 20 & 5,572 & 5,591 & & & \\
\hline & \multirow{2}{*}{ Ref.\#6 } & \multirow{2}{*}{ RT-PCR } & SR80 & TGGGATTCTACACAAAACCC & 20 & 4,366 & 4,385 & \multirow{2}{*}{320} & \multirow{2}{*}{$\begin{array}{l}\text { Thwiny } \\
\text { et al., } 2015\end{array}$} & \\
\hline & & & JV33 & GTGTANATGCARTCATCACC & 20 & 4,666 & 4,685 & & & \\
\hline & \multirow{2}{*}{ Ref.\#7 } & \multirow{2}{*}{ RT-PCR } & SLV5317 & CTCGCCACCTACRAWGCBTGGTT & 23 & 5,083 & 5,105 & \multirow{2}{*}{100} & \multirow{2}{*}{$\begin{array}{l}\text { Khamrin } \\
\text { et al., } 2011\end{array}$} & \\
\hline & & & SMP-R & CMWWCСCCTCCATYTCAAACAC & 22 & 5,161 & 5,182 & & & \\
\hline
\end{tabular}

*Based on NCBI accession number KP298674.1

여 시료 내 양성인 경우의 작동 가능성 및 검출 민감도 를 분석하였다. 지하수 시료\#1에서 12 preps. 의 total RNA 를 추출하여 $720 \mu \mathrm{L}$ 를 확보하였고, $45 \mu \mathrm{LRNA}$ 를 8 개 새로 운 tube에 분주 후 $1 \mathrm{ng} / \mu \mathrm{L}$ plasmid $5 \mu \mathrm{L}$ 를 시작으로 10 배 단계 희석하였다. 이번 연구에서 개발한 RT-nested PCR 프라이머 조합을 포함한 조성물 및 조건으로 인위적 감 염 시료에 대한 검출 민감도를 분석한 결과 RT-PCR에서 약 $10^{-4}$ 수준, nested PCR에서 약 $10^{-6}$ 수준으로 나타났으며, 순수한 plasmid 조건 대비 시료 내에서는 검출 민감도가 약 10 배 수준 감소하였다(Fig. 3B). 한편, 개발한 시험법의 밸리데이션을 위해 다른 날 다른 검사자 및 다른 기관의 연구자에 의해 특이성 및 검출 민감도 등에 대해 2회 추 가 반복 시험하여 총 3 회 시험 결과 동일한 결과가 나타 났다(자료 미 제공).

한편, 이번 연구에서 개발한 RT-PCR 및 nested PCR 프 라이머 조합이 반응할 수 있는 양성대조 물질을 제작하였 다. 실험 시 위 양성을 점검할 수 있도록 증폭 산물의 크 기를 다르게 하였고, nested PCR 증폭 후 4종류의 제한효 소가 반응할 수 있는 특정 염기서열을 포함하는 방법(Lee et al., 2011; Lee, 2013)을 적용하여 설계 후 (주) Macrogen에
서 유전자 합성하였다(Fig. 4A). 제작한 양성대조 물질을 $1 \mathrm{pg} / \mu \mathrm{L}$ 로 희석 후 개발한 PCR 및 nested PCR 프라이머 조합의 반응성을 점검하였다. Nested PCR 증폭 후 산물을 EcoRV (GAT/ATC) (New England Biolabs, Boston, USA)에 처리 후, $2 \%$ agarose gel에 전기영동 하였으며 UV 하에서 분석하였다. PCR 결과 $500 \mathrm{nt}$, nested PCR 결과 $450 \mathrm{nt}$ 의 특정 밴드가 형성되었다. $1^{\mathrm{st}} \mathrm{PCR}$ 증폭 시 $781 \mathrm{nt}, 2^{\text {nd }} \mathrm{PCR}$ 증폭 시 $491 \mathrm{nt}$ 가 나타나는 기존 $\mathrm{HuSaV}$ plasmid 및 시료에 서 증폭이 예상되는 $\mathrm{HuSaV}$ 유전자 단편의 크기와 차이 가 나타났으며, 개발한 양성대조 물질은 nested PCR 증 폭 산물에 제한효소 $\mathrm{EcoRV}$ 처리 결과 2종류 크기(322 및 $172 \mathrm{nt}$ )의 밴드가 나타났다(Fig. 4B). 이에 따라 개발한 양 성대조 물질에서 오염이 일어나 위 양성 반응이 나타나면 $1^{\mathrm{st}} \mathrm{PCR}$ 시 크기로 검정이 가능하며, $2^{\mathrm{nd}} \mathrm{PCR}$ 시 산물의 제 한효소 $\mathrm{EcoRV}$ 처리로 밴드의 절단을 확인하여 위 양성 에 대한 여부를 확인할 수 있을 것으로 사료된다.

이번 연구에서는 임상, 식품, 지하수 및 비 소독수 등 다양한 환경에서 신속하고 특이성이 높으며, 다양한 $\mathrm{HuSaV}$ 포함 하위분류군의 검출이 가능한 보다 효과적인 진단용 RT-nested PCR 프라이머 조합을 개발하고자 하였 
A
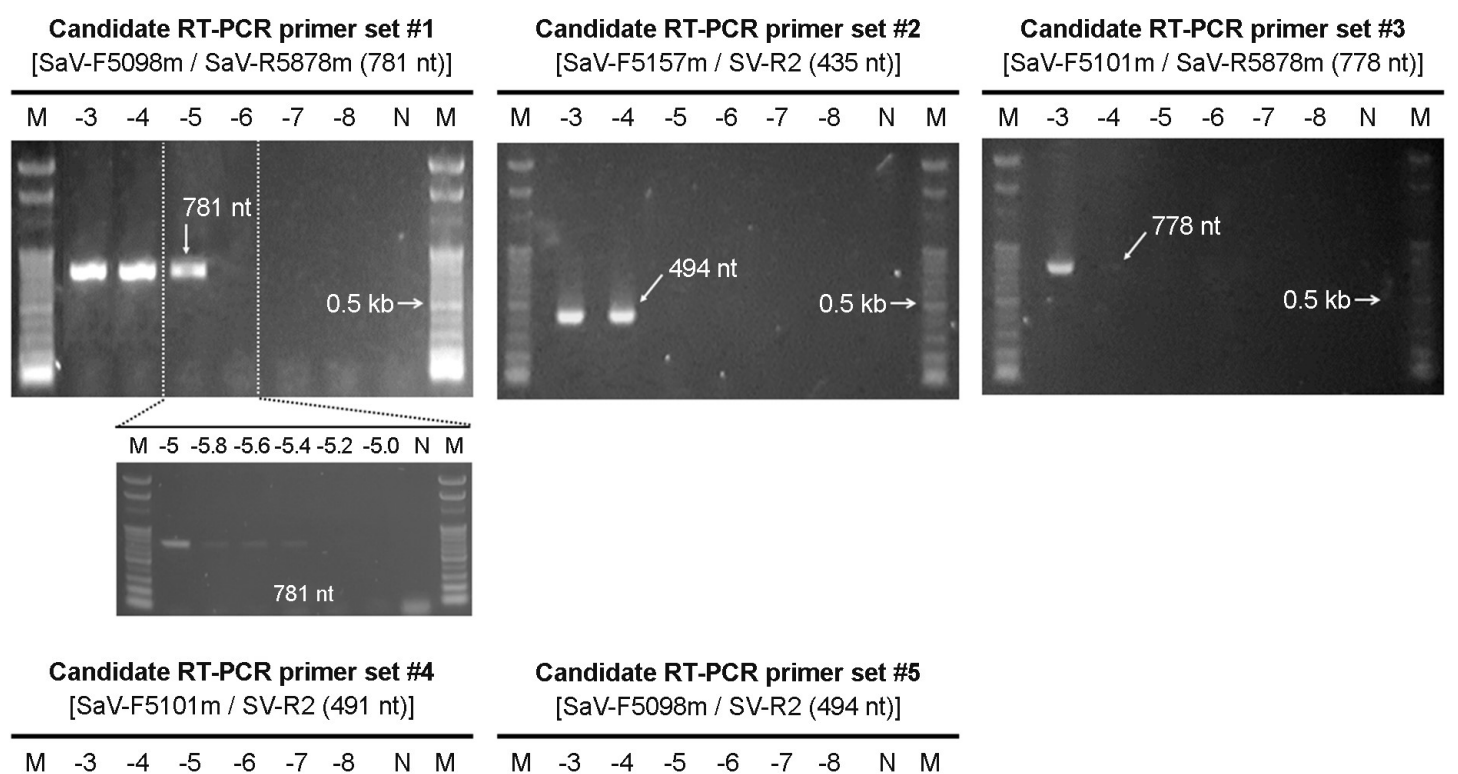

Candidate RT-PCR primer set \#5

[SaV-F5098m / SV-R2 (494 nt)]
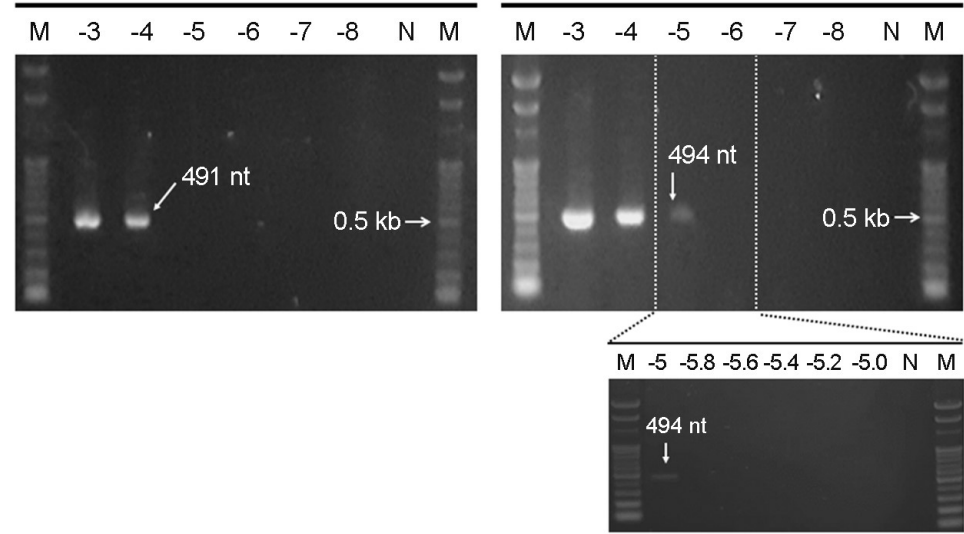

B
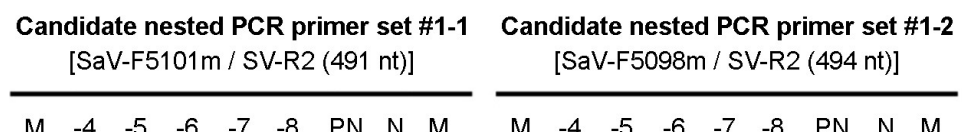

Candidate nested PCR primer set \#1-3
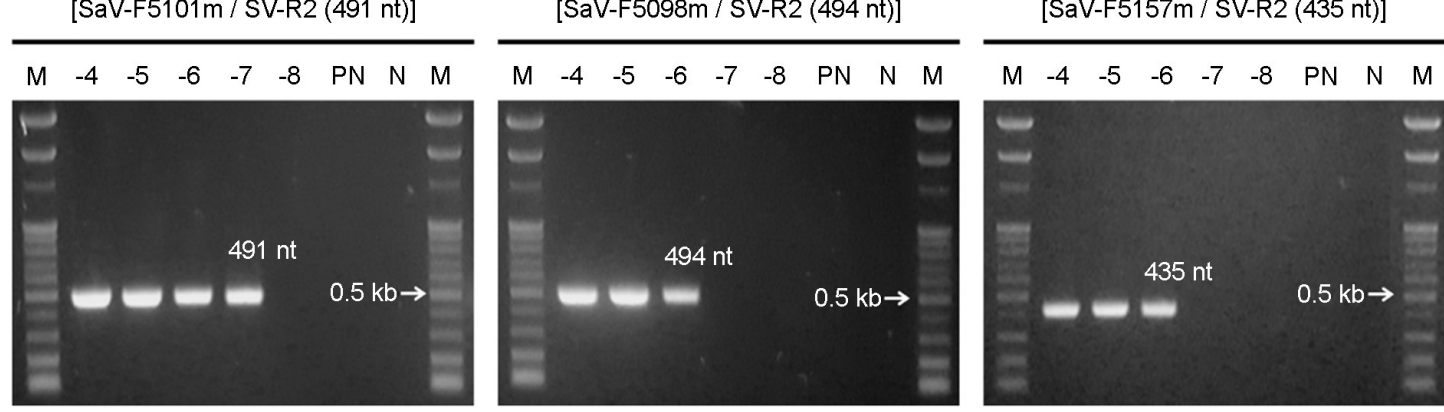

Fig. 1. Sensitivity test of candidate RT-PCR and nested primer sets for the detection of HuSaV. (A) Candidate RT-PCR primer sets (B) Candidate nested PCR primer sets. M, 100 bp Ladder marker (Enzynomics, Korea); $-3 \sim-8$, template dilution value from $1 \mathrm{ng} / \mu \mathrm{L}$ HuSaV plasmid; N, negative control, PN, PCR negative control.

다. 현재 $\mathrm{HuSaV}$ 의 진단은 특이적 반응, 검출 민감도, 분 석 난이도, 비용 등을 고려한 real-time $\mathrm{qPCR}$, 등온증폭법 (Loop-mediated isothermal amplification; LAMP), multiplex reverse-transcription PCR 등이 보고되어 있다(Cho et al., 2018; Fukuda et al., 2006; Oka et al., 2006; Shigemoto et al., 2011). 이들 중 real-time qPCR의 경우, Taq-man probe 방법 

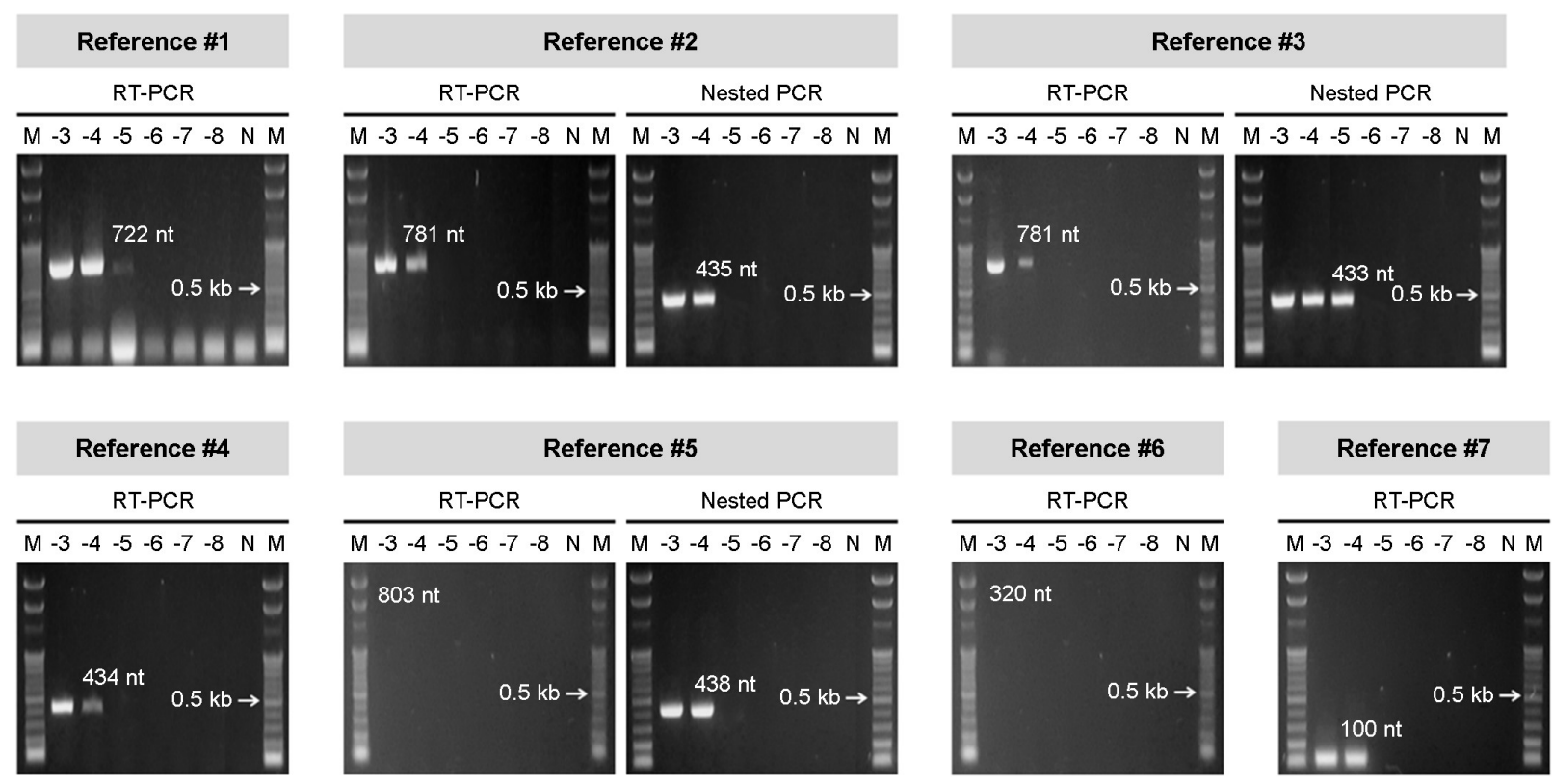

Fig. 2. Sensitivity test of seven previously reported RT-PCR or RT-nested PCR primer sets for the detection of HuSaV. M, 100 bp Ladder marker (Enzynomics); $-3 \sim-8$, template dilution value from $1 \mathrm{ng} / \mu \mathrm{L} \mathrm{HuSaV}$ plasmid; N, negative control.

(4)

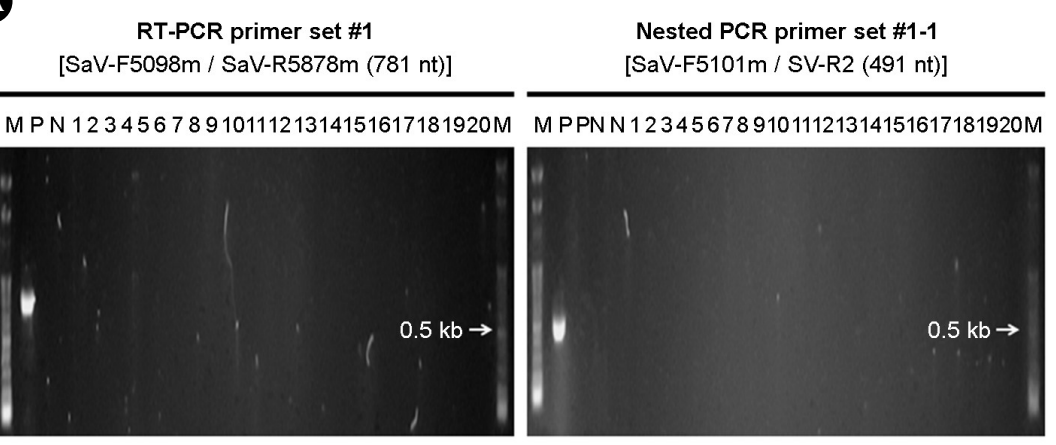

B

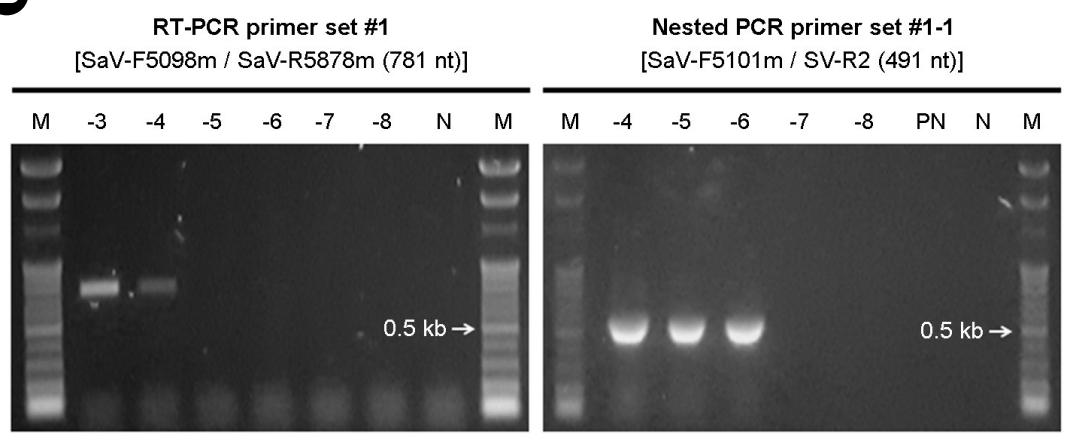

Fig. 3. Sample and artificial infection tests of developed RT-nested PCR primer set for the detection of $\mathrm{HuSaV}$ in this study. (A) HuSaV detection using the composition including RT-nested PCR primer sets and conditions developed in this study. (B) Artificial infection tests of 20 groundwater samples. M, 100 bp Ladder marker (Enzynomics); $-1 \sim-7$, template dilution value from $1 \mathrm{ng} / \mu \mathrm{L} \mathrm{HuSaV}$ plasmid; N, negative control, PN, PCR negative control.

이 일반적으로 가장 많이 사용되고 있으며(Ponchel et al., 2003) 특이성, 검출 민감도가 높고 신속한 진단이 가능한
장점을 가지고 있어 다양한 분야에서 활용이 보고(Mano et al., 2014; Botes et al., 2013; Bhullar et al., 2014) 되고 있다. 
(A)

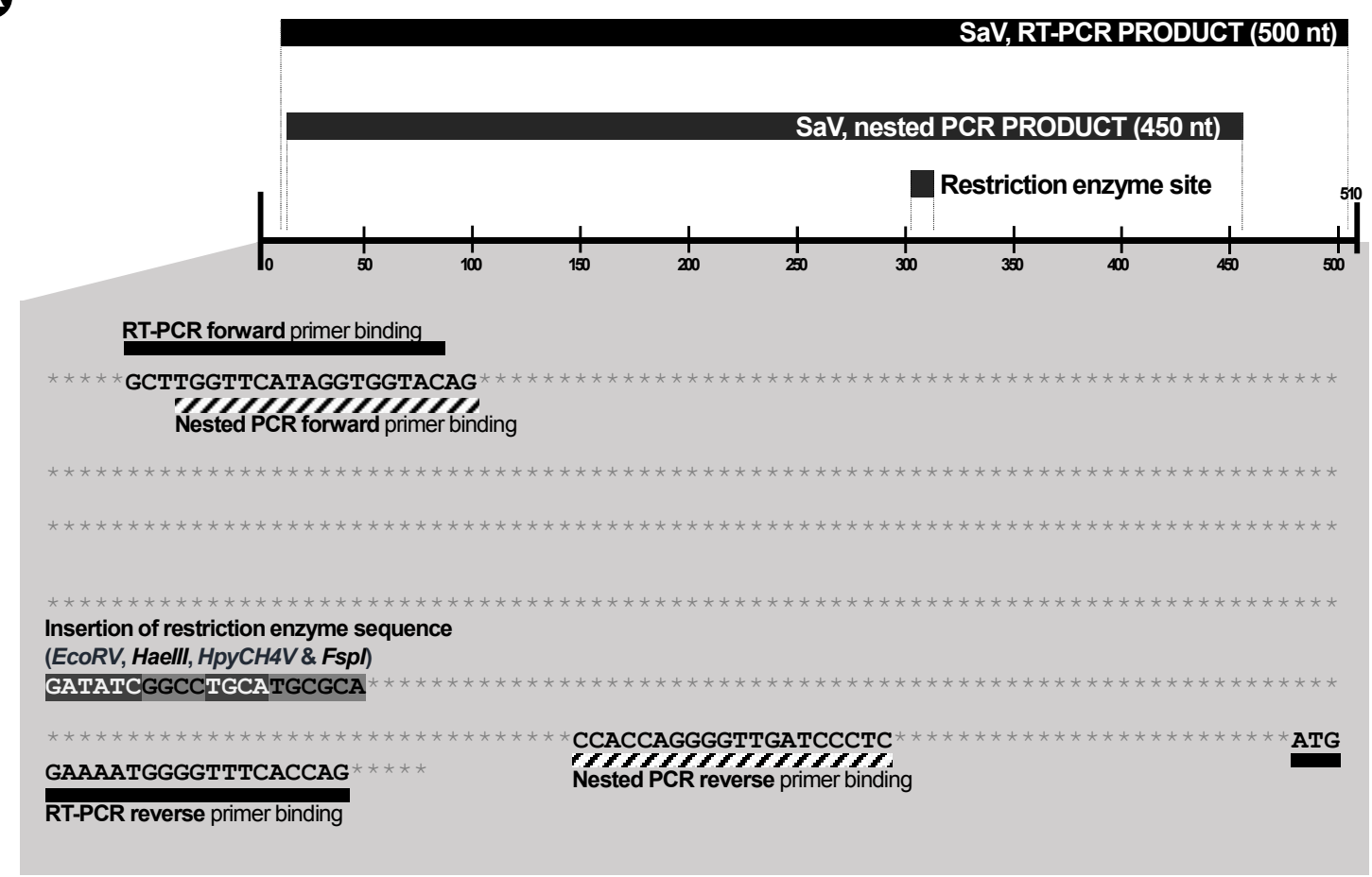

B

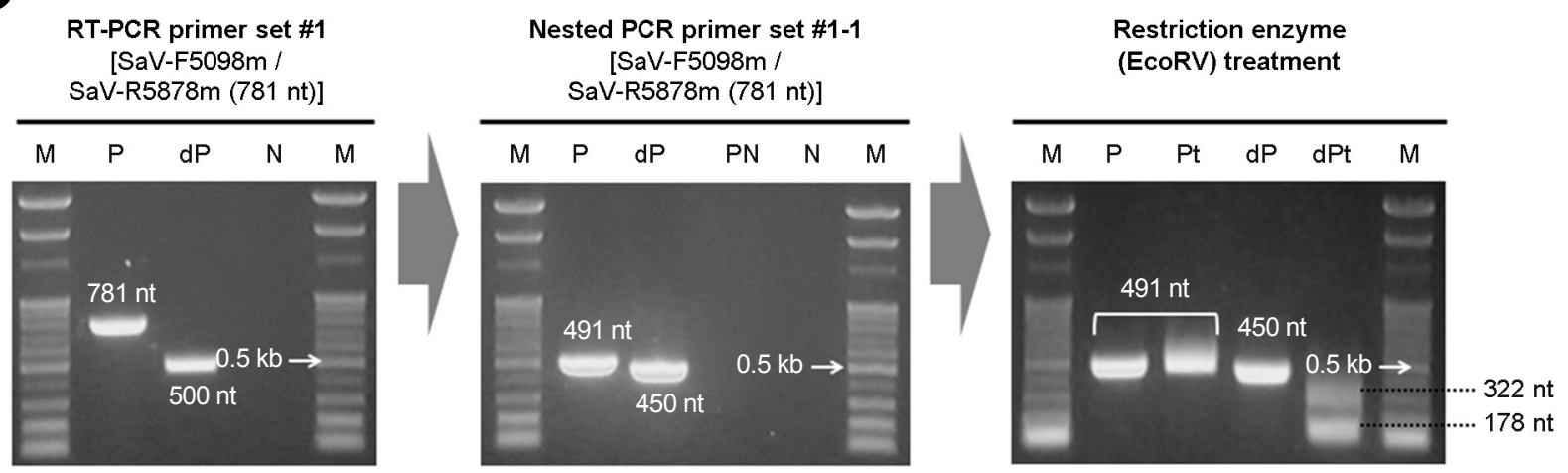

Fig. 4. The positive control design information and restriction enzyme treatment result developed in this study. (A) Design information of positive control capable of false positive test via restriction enzyme cutting from nested PCR product and amplicon size thereof. (B) Restriction enzyme EcoRV digestion of plasmid and development of positive control using the nested PCR amplicons as a template. M, 100 bp DNA Ladder marker (Enzynomics); P, plasmid; dP, developed positive control; N, negative control; PN, PCR negative control; Pt, plasmid treatment; $\mathrm{dPt}$, developed positive control treatment.

그러나 해당 플랫폼은 증폭 산물로 염기서열 분석을 할 수 없는 단점이 있다(Cho et al., 2018). 등온증폭법의 경우, 비 특이적 위 양성, 높은 비용 등의 단점이 보고되고 있 는 등(Smith and Osborn, 2009) PCR 검사 기법에 다양한 장 단점이 존재하는 것이 특징이다. 이번 연구에서 진단 방 법으로 사용한 conventional PCR의 경우, 오랜 기간 많은 연구자들에 의해 안정성이 검증되었고, 염기서열 분석이
가능하며, 상대적으로 비용, 검사자의 숙련도, 분석 난이 도 측면에서 다른 PCR 검사 기법 보다 장점을 가지고 있 어, 표준검사법으로 가장 많이 사용되고 있는 방법이다 (KCDC, 2015; KMFDS, 2015; NIER, 2016). 이에 따라 이번 연구에서는, $\mathrm{HuSaV}$ 의 genotyping을 통한 후속 유전형 분 석을 위해 conventional RT-nested PCR 방법 기반의 기술을 개발하였다. 본 연구에서 개발한 RT-nested PCR 프라이머 
는 $\mathrm{HuSaV} 38$ 개 하위분류군의 variation을 검출할 수 있도 록 설계하였다. 기존 보고된 PCR 프라이머 대비 RT-PCR 정방향 프라이머는 $2 \mathrm{nt}$ variation, RT-PCR 역방향 프라이 머는 $6 \mathrm{nt}$ variation, nested PCR 정방향 프라이머는 $2 \mathrm{nt}$ variation을 커버함에 따라 기존 방법 대비 넓은 수준의 $\mathrm{HuSaV}$ 결합이 추정되었다(자료 미 제공). 이번 연구에서 개발한 방법은 모니터링 검사기간을 거쳐 향후 지하수 등 수계 환경에서 $\mathrm{HuSaV}$ 검출을 위한 방법 등으로 활용성 이 기대된다.

\section{ACKNOWLEDGEMENT}

This work was supported by a grant from the National Institute of Environmental Research (NIER), funded by the Ministry of Environment (MOE) of the Republic of Korea (NIER-2020-01-01-003).

\section{CONFLICT OF INTEREST}

The authors declare that they have no conflict of interest.

\section{REFERENCES}

Botes M, de Kwaadsteniet M, Cloete TE. Application of quantitative PCR for the detection of microorganisms in water. Anal Bioanal Chem. 2013. 405: 91-108.

Bhullar SS, Chandak NH, Purohit H, et al. Determination of viral load by quantitative real-time PCR in herpes simplex encephalitis patients. Intervirology. 2014. 57: 1-7.

Cho KB. Development of nested PCR primer set for the specific and highly sensitive detection of human parvovirus B19. Biomed Sci Lett. 2018a. 24: 390-397.

Cho KB. Construction of Improved PCR primer set for the detection of human enteric adenovirus 41. Biomed Sci Lett. 2018b. 24: 230-238.

Cho SR, Lee DY, Jung S, et al. Pathogen surveillance of acute viral gastroenteritis in Korea in 2017. Public Health Weekly Report. 2018. 11: 1374-1380

Cho SR, Yun SJ, Chae SJ, et al. An outbreak associated with sapovirus GI.3 in an elementary school in Gyeonggi-do, Korea. J Korean Med Sci. 2020. 35: e281.

Dalecka B, Mezule L. Study of potential PCR inhibitors in drinking water for Escherichia coli identification. Agron Res. 2018. 16: 1351-1359.

Fukuda S, Takao S, Kuwayama M, Shimazu Y, Miyazaki K. Rapid detection of norovirus from fecal specimens by real-time reverse transcription-loop-mediated isothermal amplification assay. J Clin Microbiol. 2006. 44: 1376-1381.

Hwnag BM, Lee DY, Chung GT, Yoo CK. Laboratory surveillance of viral acute gastroenteritis in Korea, 2014. Public Health Weekly Report. 2015. 8: 1172-1177.

Khamrin P, Okame M, Thongprachum A, et al. A single-tube multiplex PCR for rapid detection in feces of 10 viruses causing diarrhea. J Virol Methods. 2011. 173: 390-393.

Kitajima M, Oka T, Haramoto E, et al. Detection and genetic analysis of human sapoviruses in river water in Japan. Appl Environ Microbiol. 2010. 76: 2461-2467.

Korea Centers for Disease Control and Prevention (KCDC). Practical guidelines for laboratory diagnosis of waterborne foodborne diseases. 2015. pp. 88-89. KCDC, Chungcheongbuk-do, Korea.

Korea Centers for Disease Control and Prevention (KCDC). Weekly sentinel surveillance report, PHWR. 2019. pp. 2283. KCDC, Chungcheongbuk-do, Korea.

Korea Ministry of Food and Drug Safety (KMFDS). Test method of food poisoning cause investigation. 2015. pp. 223-227. KMFDS, Chungcheongbuk-do, Korea.

Kumthip K, Khamrin P, Ushijima H, et al. Genetic recombination and diversity of sapovirus in pediatric patients with acute gastroenteritis in Thailand, 2010-2018. PeerJ. 2020. 8: e8520.

Lee S. A study of molecular biological detection methods for seed-transmitted viruses in quarantine. Ph. D. thesis. 2013. Dankook University, Cheonan, Chungcheongnam-do, Korea.

Lee SG, Lee SH, Park SW, et al. Standardized positive controls for detection of norovirus by reverse transcription PCR. Virol J. 2011. 260: 1-8

Liu X, Yamamoto D, Saito M, et al. Molecular detection and characterization of sapovirus in hospitalized children with acute gastroenteritis in the Philippines. J Clin Virol. 2015. 68: 83-88.

Mano J, Hatano S, Futo S, et al. Development of direct real-time PCR system applicable to a wide range of foods and agricultural products. Shokuhin Eiseigaku Zasshi. 2014. 55: 25-33.

NIER. Development and verification of genetically diagnostic method for the detection of non-regulated viruses from water environment (I). 2016. pp. 1-21. NIER, Incheon, Korea.

Oka T, Katayama K, Hansman GS, et al. Detection of human sapovirus by real-time reverse transcription-polymerase chain reaction. J Med Virol. 2006. 78: 1347-1353.

Oka T, Wang Q, Katayama K, Saif LJ. Comprehensive review of human sapoviruses. Clin Microbiol Rev. 2015. 28: 32-53. 
Ponchel F, Toomes C, Bransfield K, et al. Real-time PCR based on SYBR-Green I fluorescence: an alternative to the TaqMan assay for a relative quantification of gene rearrangements, gene amplifications and micro gene deletions. BMC Biotechnol. 2003. 3: 18 .

Schrader C, Schielke A, Ellerbroek L, Johne R. PCR inhibitors occurrence, properties and removal. J Appl Microbiol. 2012. 113: 1014-1026.

Shigemoto N, Fukuda S, Tanizawa Y, et al. Detection of norovirus, sapovirus, and human astrovirus in fecal specimens using a multiplex reverse transcription-PCR with fluorescent dyelabeled primers. Microbiol Immunol. 2011. 55: 369-372.

Smith CJ, Osborn AM. Advantages and limitations of quantitative
PCR (Q-PCR)-based approaches in microbial ecology. FEMS Microbiol Ecol. 2009. 67: 6-20.

Thwiny H, Hasony H. Molecular detection of human sapovirus from healthy and hospitalized children with acute gastroenteritis in Basrah. JIARM. 2015. 3: 393-403.

https://doi.org/10.15616/BSL.2021.27.1.35

Cite this article as: Lee S, Bae KS, Lee JY, Joo YL, Kim JH, You KA. Development of Molecular Diagnostic System with High Sensitivity for the Detection of Human Sapovirus from Water Environments. Biomedical Science Letters. 2021. 27: 35-43. 